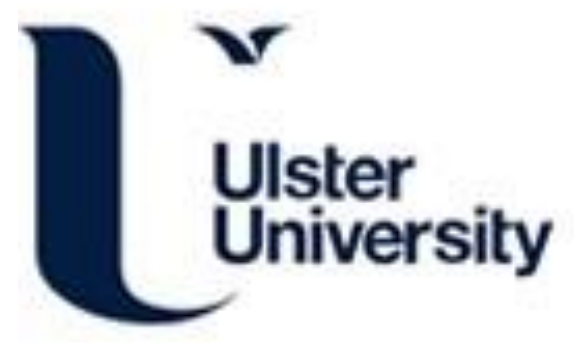

\title{
The relationship between adiposity and cognitive function in a large community- dwelling population: data from the Trinity Ulster Department of Agriculture (TUDA) ageing cohort study
}

Ntlholang, O., McCarroll, K., Laird, E., Molloy, A. M., Ward, M., McNulty, H., Hoey, L., Hughes, C., Strain, J. J., Casey, M., \& Cunningham, C. (2018). The relationship between adiposity and cognitive function in a large community-dwelling population: data from the Trinity Ulster Department of Agriculture (TUDA) ageing cohort study. British Journal of Nutrition, 120, 517-527. https://doi.org/10.1017/S0007114518001848

Link to publication record in Ulster University Research Portal

Published in:

British Journal of Nutrition

Publication Status:

Published (in print/issue): 14/09/2018

DOI:

10.1017/S0007114518001848

Document Version

Author Accepted version

\section{General rights}

Copyright for the publications made accessible via Ulster University's Research Portal is retained by the author(s) and / or other copyright owners and it is a condition of accessing these publications that users recognise and abide by the legal requirements associated with these rights.

\section{Take down policy}

The Research Portal is Ulster University's institutional repository that provides access to Ulster's research outputs. Every effort has been made to ensure that content in the Research Portal does not infringe any person's rights, or applicable UK laws. If you discover content in the Research Portal that you believe breaches copyright or violates any law, please contact pure-support@ulster.ac.uk. 
The relationship between adiposity and cognitive function in a large communitydwelling population: data from the Trinity Ulster Department of Agriculture (TUDA) ageing cohort study

Ontefetse Ntlholang ${ }^{1}$, Kevin McCarroll ${ }^{1}$, Eamon Laird ${ }^{2}$, Anne M. Molloy ${ }^{2}$, Mary Ward ${ }^{3}$, Helene McNulty ${ }^{3}$, Leane Hoey ${ }^{3}$, Catherine F. Hughes ${ }^{3}$, J.J. Strain ${ }^{3}$, Miriam Casey ${ }^{1}$, Conal Cunningham ${ }^{1}$.

${ }^{1}$ The Mercers Institute for Research on Ageing, St James's Hospital, Dublin, Ireland ${ }^{2}$ School of Medicine, Trinity College Dublin, Ireland

${ }^{3}$ Nutrition Innovation Centre for Food and Health, University of Ulster, Coleraine, United Kingdom.

Correspondence: Dr Ontefetse Ntlholang

Address: MedEl Directorate, St James's Hospital, Dublin 8, Ireland

Email: damaze2002@yahoo.com

Tel: 0035314103000

Fax: 0035314103499

Running Title: Central obesity predicts lower brain function

Keywords: adiposity, body mass index, waist-hip ratio, cognitive function, inflammation 


\section{ABSTRACT}

Previous reports between investigating adiposity and cognitive function in the population allude to a negative association, although the relationship in older adults is unclear. The aim of this study was to investigate the association of adiposity (Body Mass Index (BMI) and Waist-Hip Ratio (WHR)) with cognitive function in community dwelling older adults (>60 yrs). Participants included 5,186 adults from the Trinity, Ulster and Department of Agriculture aging cohort study. Neuropsychological assessment measures included the MiniMental State Examination (MMSE), Frontal Assessment Battery (FAB) and Repeatable Battery for the Assessment of Neuropsychological Status (RBANS). Multi-variable linear regression models were used to assess the association between adiposity and cognitive function adjusting for insulin resistance, inflammation and cerebrovascular disease. The mean (SD) ages were 80.3(6.7), 71.0(7.3) and 70.2(6.3) years on the Cognitive, Bone and Hypertensive cohorts, respectively. In the Cognitive cohort, BMI was positively associated with immediate and delay memory, visuospatial/constructional ability, language and MMSE and negatively with FAB(log-transformed) whereas WHR was negatively associated with attention. In the Bone cohort, BMI was not associated with any cognitive domain whereas WHR was negatively associated with visuospatial/constructional ability, attention and MMSE. In the Hypertensive cohort, BMI was not associated with any cognitive domain whereas WHR was negatively associated with immediate and delay memory, visuospatial/constructional ability, language and MMSE and positively with FAB(logtransformed). In the Cognitive and Bone cohorts, the association of WHR and attention disappeared by further controlling for C-Reactive Protein and HbA1C. In this study of older adults, central adiposity was a stronger predictor of poor cognitive performance than BMI. Older adults could benefit from targeted public health strategies aimed at reducing obesity and obeseogenic risk factors to avoid/prevent/slow cognitive dysfunction. 


\section{INTRODUCTION}

The number of cases of dementia is increasing in both developing and developed countries and is predicted to rise from 24.3 million in 2001 to 42.3 million in 2020 and again to 81.1 million by $2040^{(1)}$. Just over one in twelve $(8.1 \%)$ of people aged 65 years or over have dementia and 1 in five $(20.6 \%)$ have cognitive impairment without dementia (CIND) ${ }^{(2)}$. The global age-standardized prevalence of obesity doubled from $6.4 \%$ in 1980 to $12.0 \%$ in 2008 whilst overweight prevalence increased from $24.6 \%$ to $34.4 \%$ during the same 28 -year period (3).

In adults aged 19-65 years, cross-sectional studies suggest that the overweight perform worse on tests of semantic memory, visuospatial ability ${ }^{(4)}$ and executive function ${ }^{(5-7)}$ compared to normal weight participants. Prospective studies have observed lower cognitive scores and greater cognitive decline in obese versus normal weight participants, with fastest decline in those with both obesity and metabolic abnormality ${ }^{(8)}$. Furthermore, a twenty-seven year longitudinal population based study observed that obesity in middle age increased the risk of future dementia independently of comorbid conditions ${ }^{(9)}$.

In older adults aged $\geq 65$ years, the association between adiposity and cognitive function is less clear. The Neurological Diseases in Central Spain study (NEDICES) observed that obese/overweight status was associated with the lowest quartiles on cognitive testing ${ }^{(10)}$. Other studies reported negative associations of obesity and cognitive function in those with mean age of 72 years ${ }^{(11)}$ and less than 70 years ${ }^{(12)}$ versus positive association in those with mean age above 73 years and those aged 70 years and over, respectively. Conversely, better performance was shown in overweight participants with mean age of 73 years ${ }^{(13)}$ and overweight oldest-old (75-90 years) ${ }^{(4)}$ as compared to normal weight older participants. Comparison between studies is problematic as most measured specific and different cognitive domains.

The aim of this study was to determine whether adiposity, estimated by Body Mass Index (BMI)) and waist-hip ratio (WHR) was associated with cognitive function (as defined by Mini-Mental State Examination Score (MMSE), Frontal Assessment Battery (FAB) and a 
detailed neuropsychological test battery - Repeatable Battery for the Assessment of Neuropsychological Status (RBANS).

\section{Methods}

Study population

The study population comprised participants from the Trinity, Ulster and Department of Agriculture (TUDA) ageing cohort study. This was a large study of community dwelling older Irish adults (>60 years) recruited between 2008 and 2012 and designed to investigate nutritional factors, related gene-nutrient interactions and health and lifestyle factors in the development of chronic diseases of aging (cardiovascular disease (CVD), osteoporosis and dementia). A detailed description of the study population and recruitment has been published previously $\left({ }^{14-16}\right)$. In short, there were three disease defined cohorts- cognitive impairment (Cognitive), osteopaenia/osteoporosis (Bone) and hypertension (Hypertensive). The Cognitive cohort (RBANS score $\leq 80$ ) consisted of 1,699 participants who were recruited from general geriatric clinics and a day hospital at the Department of Medicine for the Elderly at St. James's Hospital, Dublin. The Bone cohort consisted of 1,394 participants who were recruited from a specialist bone health service at the Department of Medicine for the Elderly at St. James's Hospital, Dublin with a diagnosis of osteoporosis or osteopaenia (within three years of recruitment) as defined by standard WHO criteria ( $\mathrm{T}$ score of $\leq-2.5$ and $\leq-1.0$ to $>-2.5$ respectively) $\left({ }^{17}\right)$. The Hypertensive cohort consisted of 2,093 participants who were recruited from general practices in the catchment area of the Western and Northern Health and Social Care Trusts in Northern Ireland with a current diagnosis of hypertension verified by their general practitioners. Of the 5,186 participants recruited, all those whose MMSE scores were less than 24 or missing were excluded (as their cognitive performance might bias the results) as were those with a missing BMI or WHR score leaving a total of 4,439 participants for this sub-study (Figure 1). Ethical approval was granted by the relevant authorities in each jurisdiction: the Research Ethics Committee of St. James's Hospital and The Adelaide and Meath Hospital, Dublin, and the Office for Research Ethics Committees Northern Ireland (ORECNI; reference 08/NI/RO3113) with corresponding approvals from the Northern and Western Health and Social Care Trusts, Northern Ireland.

\section{Lifestyle and anthropometric information}

Data associated with lifestyle factors were obtained by questionnaire and included sex, age, ethnicity, education and medical history (including medication use). Data that were recorded 
also included current smoking and alcohol intake, falls and psychosocial history.

Anthropometric measurements included height to the nearest $0.01 \mathrm{~m}$ (using a wall-mounted stadiometer from Seca Ltd), weight to the nearest $0.01 \mathrm{~kg}$ (using electronic scales from Brosch Direct Ltd), and waist and hip circumference to the nearest $0.1 \mathrm{~cm}$ (using a flexible tape measure from Seca Ltd). BMI was calculated as weight (kilograms) divided by height (meters) squared.

\section{Cognitive and physical function measures}

Cognitive assessment measures included MMSE, total FAB and RBANS. In all participants, MMSE $^{(18)}$ was performed. The FAB is a brief battery of six neuropsychological tasks designed to assess frontal lobe function (19). These include similarities (conceptualization), lexical fluency (mental flexibility), motor series "Luria" test (programming), conflicting instructions (sensitivity to interference), Go-No Go (inhibitory control) and prehension behaviour (environmental autonomy). A cut off score of 12 on the FAB has a sensitivity of $77 \%$ and specificity of $87 \%$ in differentiating between frontal dysexecutive type dementias and dementia of Alzheimer type. RBANS has 5 indices and a total scale ${ }^{(20)}$ as follows: Index I (immediate memory), index II (visuospatial/constructional ability), index III (language), index IV (attention) and index V (delayed memory). The Timed Up and Go (TUG) test $\mathrm{t}^{(21)}$ and the Lawton Instrumental Activities of Daily Living (IADL) Scale ${ }^{(22)}$ were used as measures of frailty.

\section{Statistical analyses}

The statistical analysis was performed using the Statistical Package for Social Sciences (version 23.0; SPSS UK Ltd.; Chersey, UK). Demographic and cognitive variables were illustrated by descriptive statistics, including numbers and percentages, medians, ranges, and mean values and standard deviations. The data were checked for normality, linear relationship, multivariate normality, multicollinearity, auto-correction, homoscedasticity and outliers and the FAB score was log transformed as it was skewed. Where appropriate, oneway ANOVA or the Wilcoxon signed rank test was used for continuous variables while categorical variables were assessed by chi-square analysis. Comprehensive Meta Analysis (CMA) software was used to combine the results and provide a point estimate and assess heterogeneity. Multi-variable linear regression models were used for modelling the relationship between cognition and adiposity. Model 1 controlled for the covariates age, sex, education, frailty (TUG and IADL), current and past smoking. The data was not adjusted for 
blood pressure as one of our cohorts consisted of patients recruited on the basis of being hypertensive. In order to look at potential effect modifiers, three further analyses were pre specified based on the understanding of how adiposity might have negative consequences on cognition (i.e. insulin resistance, cerebrovascular damage and inflammation). In models 2, 3 and 4, HbA1C, cerebrovascular diseases (stroke and/or transient ischaemic attack) and creactive protein (CRP), respectively were added to model 1 .

\section{RESULTS}

Interaction terms were graphed between cohorts (online supplementary information, figure $1 S)$. There was an interaction between adiposity and cognitive tests by cohorts. Given the interaction we analysed the data for the whole cohorts and then treated each cohort separately. Cohort characteristics are presented in table 1. Participants in the Cognitive cohort were about 10 years older than the other 2 cohorts, and were more frail with higher TUG, lower IADL and lower cognitive scores, $\mathrm{p}<0.001$.

Table 2 summarizes the relationship between adiposity and cognitive function in all TUDA participants. WHR was negatively associated with cognitive function across all tests except FAB (log-transformed). BMI was positively associated with cognitive function across a number of cognitive tests except FAB (log-transformed). Tables 3, 4 and 5 details the results in the Cognitive, Bone and Hypertensive cohorts, respectively.

WHR was negatively associated with cognitive function in all 3 cohorts but effects attenuated across cohorts. The effect was strongest in Hypertensive and less so in the older Cognitive cohort. BMI was not associated with cognitive function in the Bone and Hypertensive, but was positively associated in the Cognitive cohort. The associations were generally not attenuated by any pre-specified analysis apart from two (CRP and HbA1C) factors in the Bone and Cognitive cohorts for RBANS Index IV (a measure of attention) from statistically significant to non-significant.

In the cognitive cohort, BMI was positively associated with immediate and delay memory, visuospatial/constructional ability, language and MMSE, and negatively with FAB (logtransformed), whereas WHR was negatively associated with attention. In the bone cohort, BMI was not associated with any cognitive domain, whereas WHR was negatively associated 
with visuospatial/constructional ability, attention and MMSE. In the hypertensive cohort, BMI was not associated with any cognitive domain, whereas WHR was negatively associated with immediate and delayed memory, visuospatial/constructional ability, language and MMSE and positively with FAB (logtransformed). In the cognitive and bone cohorts, the association of WHR and attention disappeared by further controlling for Creactive protein and $\mathrm{HbA} 1 \mathrm{C}$.

On meta-analysis, using the three cohorts, BMI was not statistically significantly associated with cognitive function on all RBANS subsets, MMSE or FAB(log) (online supplementary table S1). However, WHR was statistically associated with cognitive function on all RBANS subsets, MMSE and FAB $(\log )$. There was an attenuation of results from statistically significant to non-significant on adjusting for CRP in RBANS index II only (supplementary table S2). Furthermore, there was a statistically significant heterogeneity between BMI and cognitive function on RBANS Index I, III, V, total scale and FAB $(\log )$ on model 1, 2,3 and 4 with further heterogeneity on MMSE in model 2 and model 4. There was a significant heterogeneity between WHR and cognitive function on RBANS Index II on model 1, 2, 3 and 4.

\section{DISCUSSION}

This large observational study showed that was associated with poorer cognitive function in older people. We found significant and robust negative associations between a measure of central adiposity and multiple domains of cognition. In contrast, however, after adjusting for central adiposity, BMI was only associated with cognition in the oldest (cognitively impaired) cohort and that association was positive. Some associations were explained by markers of inflammation or insulin resistance. This supports that the relationship between obesity and cognition is complex and that central (rather than general) adiposity is the main driver.

Our results on the association between central adiposity, measured by WHR, and cognitive function are comparable to other studies. Dore et al. ${ }^{(6)}$ reported that waist circumference and waist/hip ratio were inversely related to cognitive function using the Wechsler Adult Intelligence Scale, the Halstead-Reitan Neuropsychological Battery, the Wechsler Memory Scale Revised, and the MMSE in adults with mean (SD) age of 62.0 (12.8) years even though the relationship was attenuated by adjusting for physical activity level. A study of 250 
participants using MMSE reported that high adiposity, particularly central adiposity, was associated with poor cognitive performance in subjects younger than 70 years, but not in those aged 70 years and over ${ }^{(12)}$. A large elderly population study (aged 60 years and over, with mean age of 70.6 years) using a Chinese version of the Mini-Mental State Examination reported that a higher waist circumference (WC) and WHR were associated with an increased prevalence of cognitive impairment ${ }^{(23)}$.

In our study, BMI was positively associated with MMSE in the Cognitive Cohort but no association was found in other cohorts. Moreover, total obesity (measured by BMI) had been found to have an insignificant effect on cognitive impairment ${ }^{(23)}$. The Neurological Diseases in Central Spain study (NEDICES) suggested that obese/overweight status, using BMI, was associated with the lowest quartiles of the 37-MMSE, Trail Making Test-A (number of errors; indeed more errors), verbal fluency, delayed free recall, immediate logical memory and pre-morbid intelligence ${ }^{(10)}$. In contrast, in our Cognitive Cohort, BMI was positively associated with immediate and delay memory, visuospatial/constructional abilities and language. The contrasting results could be explained by the fact that we controlled for BMI and WHR rather than BMI alone.

Nilson and Nilson ${ }^{(4)}$ examining the oldest old (75-90 years) reported that overweight (BMI) subjects performed significantly better on visuospatial ability than those with normal weight. This is further supported by a study of 2684 individuals aged 65-94 years with mean age of 73 years that showed overweight (BMI) subjects had better performance in terms of reasoning and visuospatial speed of processing than normal-weight participants ${ }^{(13)}$. The Cardiovascular Health Study ${ }^{(24)}$, mean age over 73 years, revealed that high adiposity (WC and BMI) and high fat-free mass in the elderly were related to slower cognitive decline measured with the modified MMSE, the Digit Symbol Substitution Test, and a composite of both.

BMI measures total adiposity whereas WC and WHR measure central adiposity. Whether BMI is a good measure of adiposity in older people is unclear owing to the fact that weight does not differentiate between fat and fat-free mass and unreliable measures of height due to shrinkage and vertebral collapse ${ }^{(25)}$. A large study of subjects aged 75 years and over $(n=14$ 833 ) in the UK reported an inverse association of BMI with mortality in women and no association in men, with WHR being positively related to circulatory mortality in both men 
and women ${ }^{(25)}$. Moreover, Hermsdorff et al. ${ }^{(26)}$ found that central adiposity-related indicators (WC/WHR) correlated better than those assessing total adiposity with plasma proinflammatory markers.

In the Cognitive and Bone cohorts, WHR and attention (digit span and coding) association disappeared by further controlling for $\mathrm{HbA} 1 \mathrm{C}$. $\mathrm{HbA} 1 \mathrm{C}$ was used as a surrogate marker for diabetes mellitus/insulin resistance. Our results suggest that insulin resistance may modify the association between cognitive function and WHR. Abbatecola et al. $\left({ }^{28)}\right.$ reported that total fat mass and central adiposity (WC and WHR) predicted an increased risk for cognitive decline in older person with diabetes ${ }^{(28)}$. The proposed mechanism of cognitive decline in diabetes is through hippocampal insulin resistance in addition to or separate from inflammation.

The association between WHR and attention disappeared by further controlling for CRP in the Bone and Cognitive cohorts. This implies that inflammation may have a role in explaining attention deficits. Obesity is a proinflammatory state with elevated levels of cytokines including TNF- $\alpha$, interleukin 6 (IL-6) ${ }^{(29)}$. Investigation of systemic markers of inflammation revealed that higher levels of CRP and IL-6 were cross-sectionally associated with worse global cognition and executive function in the Rotterdam Study while only IL-6 in the Leiden 85 -plus Study ${ }^{(30)}$. Furthermore, plasma levels of inflammatory proteins are reported to be increased before clinical onset of dementia ${ }^{(31)}$.

Even though cerebrovascular diseases did not attenuate the relationship between adiposity and cognitive function on analysis in our study, it is known to affect cognitive function. Obesity is a known vascular risk factor that predisposes individuals to Alzheimer's disease and vascular dementia ${ }^{(32)}$. The postulated mechanism is through blood-brain barrier dysfunction leading to hypoperfusion and as a result increased accumulation of $\beta$-amyloid ${ }^{(32)}$. Blood-brain barrier dysfunction is associated with both Alzheimer's disease and vascular dementia among very elderly individuals ${ }^{(33)}$. Our failure to detect an attenuation could be due to the small number of participants with cerebrovascular disease in the current study or the fact that subjects with dementia were excluded. Alternatively cerebrovascular disease may not have been an important mechanism through which obesity affected cognitive function in our subjects. 
The association between adiposity and cognitive function was not attenuated by any prespecified analyses in the hypertensive group. Perhaps there was no attenuation due to the fact that hypertension itself is associated with inflammation. Hypertension is associated with insulin resistance ${ }^{(34)}$ and inflammation, with CRP being the inflammatory marker with the strongest association ${ }^{(35)}$. Singer et al. ${ }^{(36)}$ using the original cohort of the Framingham Heart Study reported that $\mathrm{HbA1C}$ was associated with hypertension. Furthermore, the ATTICA study revealed an association between prehypertension and inflammatory markers linked to the atherosclerotic process including $\mathrm{CRP}^{(37)}$.

The major strengths of this study include the study size, the well characterized population and a comprehensive battery of cognitive tests. We used a full neuropsychological test battery RBANS to measure specific cognitive performances ie attention, language, visuospatial/constructional abilities, and immediate and delayed memory and analyse them individually unlike other studies. Additionally, the statistical analysis was able to adjust for a wide range of confounders and covariates not usually recorded. There are some limitations; this is a cross-sectional study and hence cannot explain causal relationship. In particular we cannot exclude reverse causation. Singh-Manoux et al. ${ }^{(38)}$ reported either an attenuated or reversed risk of dementia associated with obesity at older ages.

It was not possible to adjust for physical activity even though it has been previously shown to have a positive impact on cognitive function while bio impedance tests were unavailable to accurately assess the true scale of the adiposity.

In conclusion, this is one of the largest studies of older adults to demonstrate that central adiposity is associated with subtle cognitive impairment in community dwelling older adults. Given the high prevalence of overweight and obesity in the older population and the economic and social burden of cognitive dysfunction, reducing- obesity and exposure to obesogenic risk factors could be a cost effective and effective public health strategy for the prevention of dementia and cognitive impairment in older adults.

\section{ACKNOWLEDGMENTS}

The authors are grateful to help received from all members of TUDA study group.

\section{FINANCIAL SUPPORT}


We acknowledge funding from the Mercer's Institute for Research on Ageing, the Irish Department of Agriculture, Food \& the Marine and Health Research Board, and the Department for Employment and Learning Northern Ireland under its Cross-Border Research and Development Programme: 'Strengthening the all-Island Research Base'.

\section{CONFLICT OF INTEREST:}

All authors declare that there are no competing interests

\section{AUTHORSHIP}

ON acquisition of data, analysis, interpretation and preparation of manuscript, KM, EL, AM, MW, HM, LH, CH, JJS, MC, CC study concept and design, acquisition of subjects and/or data, KM, EL, CC study concept and design, acquisition of data, analysis, interpretation of data, critical revision.

All authors approved the final submitted version

\section{SPONSOR'S ROLE: none}

\section{References}

1. Rizzi L, Rosset I, Roriz-Cruz M (2014) Global epidemiology of dementia: Alzheimer's and vascular types. BioMed research international 2014, 908915.

2. Prencipe M, Santini M, Casini AR, et al. (2003) Prevalence of non-dementing cognitive disturbances and their association with vascular risk factors in an elderly population. Journal of neurology 250, 907-12.

3. Stevens GA, Singh GM, Lu Y, et al. (2012) National, regional, and global trends in adult overweight and obesity prevalences. Population health metrics 10, 22.

4. Nilsson LG, Nilsson E (2009) Overweight and cognition. Scandinavian journal of psychology 50, 660-7.

5. Gunstad J, Paul RH, Cohen RA, et al. (2007) Elevated body mass index is associated with executive dysfunction in otherwise healthy adults. Comprehensive psychiatry $48,57-$ 61.

6. Dore GA, Elias MF, Robbins MA, et al. (2008) Relation between central adiposity and cognitive function in the Maine-Syracuse Study: attenuation by physical activity. Annals of behavioral medicine : a publication of the Society of Behavioral Medicine 35, 341-50. 7. Lokken KL, Boeka AG, Yellumahanthi K, et al. (2010) Cognitive performance of morbidly obese patients seeking bariatric surgery. The American surgeon 76, 55-9. 8. Singh-Manoux A, Czernichow S, Elbaz A, et al. (2012) Obesity phenotypes in midlife and cognition in early old age: the Whitehall II cohort study. Neurology 79, 755-62. 9. Whitmer RA, Gunderson EP, Barrett-Connor E, et al. (2005) Obesity in middle age and future risk of dementia: a 27 year longitudinal population based study. Bmj 330, 1360. 
10. Benito-Leon J, Mitchell AJ, Hernandez-Gallego J, et al. (2013) Obesity and impaired cognitive functioning in the elderly: a population-based cross-sectional study (NEDICES). European journal of neurology 20, 899-906, e76-7.

11. Smith E, Hay P, Campbell L, et al. (2011) A review of the association between obesity and cognitive function across the lifespan: implications for novel approaches to prevention and treatment. Obesity reviews : an official journal of the International Association for the Study of Obesity 12, 740-55.

12. Yoon DH, Choi SH, Yu JH, et al. (2012) The relationship between visceral adiposity and cognitive performance in older adults. Age and ageing 41, 456-61.

13. Kuo HK, Jones RN, Milberg WP, et al. (2006) Cognitive function in normal-weight, overweight, and obese older adults: an analysis of the Advanced Cognitive Training for Independent and Vital Elderly cohort. Journal of the American Geriatrics Society 54, 97103.

14. McCarroll K, Beirne A, Casey M, et al. (2015) Determinants of 25-hydroxyvitamin $\mathrm{D}$ in older Irish adults. Age and ageing 44, 847-53.

15. Laird E, McNulty H, Ward M, et al. (2014) Vitamin D deficiency is associated with inflammation in older Irish adults. The Journal of clinical endocrinology and metabolism 99, 1807-15.

16. Molloy AM, Pangilinan F, Mills JL, et al. (2016) A Common Polymorphism in HIBCH Influences Methylmalonic Acid Concentrations in Blood Independently of Cobalamin. American journal of human genetics 98, 869-82.

17. Report of a World Health Organization Study Group (1994) Assessment of fracture risk and its application to screening for mostmenopausal osteoporosis. World Health Organ Tech Rep Ser 843, 1-129.

18. Folstein MF, Folstein SE, McHugh PR (1975) "Mini-mental state". A practical method for grading the cognitive state of patients for the clinician. Journal of psychiatric research 12, 189-98.

19. Dubois B, Slachevsky A, Litvan I, et al. (2000) The FAB: a Frontal Assessment Battery at bedside. Neurology 55, 1621-6.

20. Randolph C, Tierney MC, Mohr E, et al. (1998) The Repeatable Battery for the Assessment of Neuropsychological Status (RBANS): preliminary clinical validity. Journal of clinical and experimental neuropsychology 20,310-9.

21. Podsiadlo D, Richardson S (1991) The timed "Up \& Go": a test of basic functional mobility for frail elderly persons. Journal of the American Geriatrics Society 39, 142-8.

22. Lawton MP, Brody EM (1969) Assessment of older people: self-maintaining and instrumental activities of daily living. The Gerontologist 9, 179-86.

23. Cui GH, Guo HD, Xu RF, et al. (2013) The association of weight status with cognitive impairment in the elderly population of a Shanghai suburb. Asia Pacific journal of clinical nutrition $22,74-82$.

24. Luchsinger JA, Biggs ML, Kizer JR, et al. (2013) Adiposity and cognitive decline in the cardiovascular health study. Neuroepidemiology 40, 274-81.

25. Price GM, Uauy R, Breeze E, et al. (2006) Weight, shape, and mortality risk in older persons: elevated waist-hip ratio, not high body mass index, is associated with a greater risk of death. The American journal of clinical nutrition 84, 449-60.

26. Hermsdorff HH, Zulet MA, Puchau B, et al. (2011) Central adiposity rather than total adiposity measurements are specifically involved in the inflammatory status from healthy young adults. Inflammation 34, 161-70.

27. Abbatecola AM, Lattanzio F, Spazzafumo L, et al. (2010) Adiposity predicts cognitive decline in older persons with diabetes: a 2-year follow-up. PloS one 5, e10333. 
28. Biessels GJ, Reagan LP (2015) Hippocampal insulin resistance and cognitive dysfunction. Nature reviews Neuroscience 16, 660-71.

29. Greenberg AS, Obin MS (2006) Obesity and the role of adipose tissue in inflammation and metabolism. The American journal of clinical nutrition 83, 461S-5S.

30. Schram MT, Euser SM, de Craen AJ, et al. (2007) Systemic markers of inflammation and cognitive decline in old age. Journal of the American Geriatrics Society 55, 708-16.

31. Engelhart MJ, Geerlings MI, Meijer J, et al. (2004) Inflammatory proteins in plasma and the risk of dementia: the rotterdam study. Archives of neurology 61, 668-72.

32. Zlokovic BV (2011) Neurovascular pathways to neurodegeneration in Alzheimer's disease and other disorders. Nature reviews Neuroscience 12, 723-38.

33. Skoog I, Wallin A, Fredman P, et al. (1998) A population study on blood-brain barrier function in 85-year-olds: relation to Alzheimer's disease and vascular dementia. Neurology 50, 966-71.

34. Soleimani M (2015) Insulin resistance and hypertension: new insights. Kidney international 87, 497-9.

35. Dinh QN, Drummond GR, Sobey CG, et al. (2014) Roles of inflammation, oxidative stress, and vascular dysfunction in hypertension. BioMed research international 2014, 406960 .

36. Singer DE, Nathan DM, Anderson KM, et al. (1992) Association of HbA1c with prevalent cardiovascular disease in the original cohort of the Framingham Heart Study. Diabetes 41, 202-8.

37. Chrysohoou C, Pitsavos C, Panagiotakos DB, et al. (2004) Association between prehypertension status and inflammatory markers related to atherosclerotic disease: The ATTICA Study. American journal of hypertension 17, 568-73.

38. Singh-Manoux A, Dugravot A, Shipley M, et al. (2018) Obesity trajectories and risk of dementia: 28 years of follow-up in the Whitehall II Study. Alzheimer's \& dementia : the journal of the Alzheimer's Association 14, 178-86. 


\section{FIGURE LEGENDS}

Figure 1: The Trinity Ulster Department of Agriculture (TUDA) Study Population. *missing or incomplete data

Figure 1S: Interaction between TUDA cohorts. All figures show an interaction between adiposity and cognitive tests by cohorts 
Table 1: TUDA Cohort Characteristics $(\mathrm{N}=4439)$

\begin{tabular}{|c|c|c|c|c|}
\hline \multicolumn{5}{|c|}{ Cohort Characteristics } \\
\hline & $\begin{array}{l}\text { Cognitive } \\
\mathrm{N}=1282\end{array}$ & $\begin{array}{l}\text { Bone } \\
\mathrm{N}=1248\end{array}$ & $\begin{array}{l}\text { Hypertensive } \\
\mathrm{N}=1909\end{array}$ & P-Value \\
\hline \multicolumn{5}{|l|}{ Demographics } \\
\hline Age (yrs) & $80.3(6.7)$ & $71.0(7.3)$ & $70.2(6.3)$ & $<0.001^{*}$ \\
\hline Sex (female, $n(\%))$ & $856(66.8)$ & $1067(85.5)$ & $1078(56.5)$ & $<0.001^{!}$ \\
\hline Education (yrs) (median) & 10 & 12 & 11 & $<0.001^{\mathrm{c}}$ \\
\hline $\begin{array}{l}\text { Body Mass Index }\left(\mathrm{kg} / \mathrm{m}^{2}\right), \\
\text { mean }(\mathrm{SD})\end{array}$ & $27.1(5.5)$ & $26.3(5.0)$ & $29.7(5.0)$ & $<0.001^{*}$ \\
\hline Waist Hip Ratio, mean(SD) & $0.91(0.08)$ & $0.87(0.08)$ & $0.93(0.08)$ & $<0.001^{*}$ \\
\hline $\begin{array}{l}\text { Timed Up and Go (TUG) (sec), } \\
\text { mean (SD) }\end{array}$ & $21.4(10.5)$ & $9.7(4.7)$ & $10.1(4.0)$ & $<0.001^{*}$ \\
\hline $\begin{array}{l}\text { Total Instrumental Activities of } \\
\text { Daily Living (IADL), mean (SD) }\end{array}$ & $21.0(4.1)$ & $25.9(2.7)$ & $26.3(2.5)$ & $<0.001^{*}$ \\
\hline \multicolumn{5}{|l|}{ Medical Morbidity } \\
\hline Hypertension, (\%) & 64.5 & 41.7 & 97.9 & $<0.001^{!}$ \\
\hline Diabetes Mellitus (\%) & 13.1 & 5.0 & 16.5 & $<0.001^{!}$ \\
\hline $\begin{array}{l}\text { Cerebrovascular disease } \\
\text { (Transient Ischaemic Attack } \\
\text { and/or Stroke) }(\%)\end{array}$ & 26.3 & 6.3 & 9.0 & $<0.001^{!}$ \\
\hline Myocardial Infarction (\%) & 12.1 & 4.4 & 11.2 & $<0.001^{!}$ \\
\hline \multicolumn{5}{|l|}{ Lifestyle Factors } \\
\hline \multicolumn{5}{|l|}{ Alcohol } \\
\hline Alcohol (current) (\%) & 49.1 & 69.2 & 58.3 & $<0.001^{!}$ \\
\hline Alcohol (past) (\%) & 23.6 & 11.2 & 16.2 & $<0.001^{!}$ \\
\hline \multicolumn{5}{|l|}{ Smoking } \\
\hline Smoking (current) (\%) & 11.6 & 14.8 & 10.6 & $0.001^{!}$ \\
\hline Smoking (past) (\%) & 42.6 & 37.7 & 42.9 & $0.008^{!}$ \\
\hline \multicolumn{5}{|l|}{ Biochemical tests } \\
\hline $\mathrm{HbAlC}^{+}$, mean(SD) & $5.87(0.68)$ & $5.69(0.52)$ & $5.95(0.94)$ & $<0.001^{*}$ \\
\hline $\mathrm{CRP}$, mean $(\mathrm{SD})$ & $7.02(12.79)$ & $4.85(13.19)$ & $3.29(7.30)$ & $<0.001^{*}$ \\
\hline \multicolumn{5}{|l|}{ Cognitive Tests } \\
\hline \multicolumn{5}{|l|}{ RBANS } \\
\hline Index I, mean(SD) & $88.7(15.8)$ & $97.9(15.9)$ & $90.6(15.9)$ & $<0.001^{*}$ \\
\hline Index II, mean(SD) & $82.0(18.1)$ & $91.5(18.4)$ & $95.6(17.9)$ & $<0.001^{*}$ \\
\hline Index III, mean(SD) & $86.6(13.0)$ & $94.7(11.4)$ & $94.0(9.7)$ & $<0.001^{*}$ \\
\hline Index IV, mean(SD) & $81.1(14.1)$ & $93.5(16.8)$ & $93.8(16.4)$ & $<0.001^{*}$ \\
\hline Index V, mean(SD) & $83.5(17.5)$ & $94.8(14.7)$ & $89.6(16.2)$ & $<0.001^{*}$ \\
\hline Total Scale, mean(SD) & $79.9(14.1)$ & $92.8(15.6)$ & $90.3(14.2)$ & $<0.001^{*}$ \\
\hline MMSE, mean(SD) & $27.1(1.7)$ & $27.9(1.6)$ & $27.9(1.4)$ & $<0.001^{*}$ \\
\hline $\mathrm{FAB}$, mean(SD) & $15.0(2.7)$ & $16.2(2.0)$ & $16.0(1.8)$ & $<0.001^{*}$ \\
\hline
\end{tabular}

"Oneway ANOVA test,'Chi-square test, ${ }^{\circ}$ Wilcoxon signed rank test, ${ }^{+} \mathrm{n}=4291$

RBANS- Repeatable Battery for the Assessment of Neuropsychological Status

SD- standard deviation, FAB- Frontal Assessment Battery,

MMSE- Mini-Mental State Examination

HBAlC- Haemoglobin AlC

CRP- C-Reactive Protein

Table 2: Adiposity versus Cognitive function in TUDA Cohorts $(\mathrm{N}=4439)$ 


\begin{tabular}{|c|c|c|c|c|c|c|c|c|}
\hline \multirow[b]{2}{*}{ Cognitive Test } & \multicolumn{2}{|l|}{ Model 1} & \multicolumn{2}{|c|}{ Model 2} & \multicolumn{2}{|c|}{ Model 3} & \multicolumn{2}{|l|}{ Model 4} \\
\hline & $\beta(\mathbf{S E})$ & P-value & $\beta(\mathbf{S E})$ & P-value & $\beta(\mathbf{S E})$ & P-value & $\beta(\mathbf{S E})$ & P-value \\
\hline RBANS Index I & \multicolumn{2}{|c|}{$\mathrm{R}^{2}=0.163$} & \multicolumn{2}{|c|}{$\mathrm{R}^{2}=0.170$} & \multicolumn{2}{|c|}{$\mathrm{R}^{2}=0.164$} & \multicolumn{2}{|c|}{$\mathrm{R}^{2}=0.168$} \\
\hline BMI & $0.060(0.048)$ & 0.210 & $0.069(0.049)$ & 0.165 & $0.059(0.048)$ & 0.217 & $0.045(0.049)$ & 0.358 \\
\hline WHR & $-19.318(3.410)$ & $<0.001$ & $-18.654(3.488)$ & $<0.001$ & $-19.265(3.409)$ & $<0.001$ & $-18.101(3.456)$ & $<0.001$ \\
\hline RBANS Index II & \multicolumn{2}{|c|}{$\mathrm{R}^{2}=0.241$} & \multicolumn{2}{|c|}{$\mathrm{R}^{2}=0.248$} & \multicolumn{2}{|c|}{$\mathrm{R}^{2}=0.243$} & \multicolumn{2}{|c|}{$\mathrm{R}^{2}=0.217$} \\
\hline BMI & $0.127(0.060)$ & 0.017 & $0.129(0.055)$ & 0.019 & $0.125(0.053)$ & 0.019 & $0.128(0.055)$ & 0.019 \\
\hline WHR & $-14.261(4.212)$ & $<0.001$ & $-13.938(3.883)$ & $<0.001$ & $-14.125(3.785)$ & $<0.001$ & $-16.388(3.866)$ & $<0.001$ \\
\hline RBANS Index III & \multicolumn{2}{|c|}{$\mathrm{R}^{2}=0.156$} & \multicolumn{2}{|c|}{$\mathrm{R}^{2}=0.165$} & \multicolumn{2}{|c|}{$\mathrm{R}^{2}=0.157$} & \multicolumn{2}{|c|}{$\mathrm{R}^{2}=0.161$} \\
\hline BMI & $0.196(0.035)$ & $<0.001$ & $0.218(0.036)$ & $<0.001$ & $0.195(0.035)$ & $<0.001$ & $0.203(0.035)$ & $<0.001$ \\
\hline WHR & $-7.544(2.475)$ & 0.002 & $-7.511(2.516)$ & 0.003 & $-7.508(2.474)$ & 0.002 & $-7.086(2.511)$ & 0.005 \\
\hline RBANS Index IV & \multicolumn{2}{|c|}{$\mathrm{R}^{2}=0.249$} & \multicolumn{2}{|c|}{$\mathrm{R}^{2}=0.256$} & \multicolumn{2}{|c|}{$\mathrm{R}^{2}=0.252$} & \multicolumn{2}{|c|}{$\mathrm{R}^{2}=0.251$} \\
\hline BMI & $0.043(0.048)$ & 0.361 & $0.059(0.049)$ & 0.225 & $0.041(0.048)$ & 0.386 & $0.047(0.048)$ & 0.332 \\
\hline WHR & $-8.338(3.374)$ & 0.013 & $-7.182(3.456)$ & 0.038 & $-8.179(3.369)$ & 0.015 & $-8.079(3.431)$ & 0.019 \\
\hline RBANS Index V & \multicolumn{2}{|c|}{$\mathrm{R}^{2}=0.149$} & \multicolumn{2}{|c|}{$\mathrm{R}^{2}=0.150$} & \multicolumn{2}{|c|}{$\mathrm{R}^{2}=0.149$} & \multicolumn{2}{|c|}{$\mathrm{R}^{2}=0.151$} \\
\hline BMI & $0.133(0.050)$ & 0.008 & $0.130(0.052)$ & 0.012 & $0.133(0.050)$ & 0.008 & $0.125(0.051)$ & 0.014 \\
\hline WHR & $-16.899(3.540)$ & $<0.001$ & $-18.365(3.642)$ & $<0.001$ & $-16.867(3.540)$ & $<0.001$ & $-15.897(3.606)$ & $<0.001$ \\
\hline RBANS Total Scale & \multicolumn{2}{|c|}{$\mathrm{R}^{2}=0.300$} & \multicolumn{2}{|c|}{$\mathrm{R}^{2}=0.308$} & \multicolumn{2}{|c|}{$\mathrm{R}^{2}=0.301$} & \multicolumn{2}{|c|}{$\mathrm{R}^{2}=0.303$} \\
\hline BMI & $0.126(0.042)$ & 0.003 & $0.139(0.043)$ & 0.001 & $0.124(0.042)$ & 0.003 & $0.117(0.043)$ & 0.006 \\
\hline WHR & $-17.201(2.988)$ & $<0.001$ & $-17.070(3.055)$ & $<0.001$ & $-17.081(2.985)$ & $<0.001$ & $-16.332(3.038)$ & $<0.001$ \\
\hline MMSE & \multicolumn{2}{|c|}{$\mathrm{R}^{2}=0.172$} & \multicolumn{2}{|c|}{$\mathrm{R}^{2}=0.176$} & \multicolumn{2}{|c|}{$\mathrm{R}^{2}=0.173$} & $\mathrm{R}^{2}=$ & .173 \\
\hline BMI & $0.005(0.005)$ & 0.304 & $0.004(0.005)$ & 0.401 & $0.005(0.005)$ & 0.314 & $0.004(0.005)$ & 0.460 \\
\hline WHR & $-1.264(0.333)$ & $<0.001$ & $-1.293(0.342)$ & $<0.001$ & $-1.259(0.333)$ & $<0.001$ & $-1.153(0.339)$ & 0.001 \\
\hline FAB $(\log )$ & $\mathrm{R}^{2}=$ & 166 & $\mathrm{R}^{2}=0$ & & $\mathrm{R}^{2}=$ & .166 & $\mathrm{R}^{2}=$ & 0.164 \\
\hline BMI & $-0.002(0.001)$ & 0.063 & $-0.002(0.001)$ & 0.043 & $-0.002(0.001)$ & 0.064 & $-0.001(0.001)$ & 0.112 \\
\hline WHR & $0.217(0.062)$ & $<0.001$ & $0.203(0.063)$ & 0.001 & $0.217(0.062)$ & $<0.001$ & $0.191(0.063)$ & 0.001 \\
\hline
\end{tabular}

Model 1: Age, Education (Duration schooling), Sex (male), BMI, WHR, Current smoker, Past smoker, TUG, Total IADL

Model 2: Model $1+$ Haemoglobin A1C (HbA1C)

Model 3: Model 1 + cerebrovascular diseases(transient ischaemic attack and/or stroke)

Model 4: Model 1 + c-reactive protein (CRP) 
Abbreviations: BMI-Body Mass Index, WHR- Waist-Hip Ratio, TUG- Timed-Up-and-Go, IADL- Instrumental Activities of Daily Living, MMSE-Mini-Mental State Examination, FAB-Frontal Assessment Battery, RBANS-Repeatable Battery for the Assessment of

Neuropsychological Status

Table 3: Adiposity versus Cognitive function in TUDA Cognitive Cohort $(\mathrm{N}=1282)$

\begin{tabular}{|c|c|c|c|c|c|c|c|c|}
\hline \multirow[b]{2}{*}{ Cognitive Test } & \multicolumn{2}{|c|}{ Model 1} & \multicolumn{2}{|c|}{ Model 2} & \multicolumn{2}{|c|}{ Model 3} & \multicolumn{2}{|l|}{ Model 4} \\
\hline & $\beta(\mathbf{S E})$ & P-value & $\beta(\mathbf{S E})$ & P-value & $\beta(\mathbf{S E})$ & P-value & $\beta(\mathbf{S E})$ & P-value \\
\hline RBANS Index I & \multicolumn{2}{|c|}{$\mathrm{R}^{2}=0.144$} & \multicolumn{2}{|c|}{$\mathrm{R}^{2}=0.144$} & \multicolumn{2}{|c|}{$\mathrm{R}^{2}=0.144$} & \multicolumn{2}{|c|}{$\mathrm{R}^{2}=0.148$} \\
\hline BMI & $0.349(0.084)$ & $<0.001$ & $0.365(0.092)$ & $<0.001$ & $0.349(0.084)$ & $<0.001$ & $0.342(0.084)$ & $<0.001$ \\
\hline WHR & $-9.051(5.957)$ & 0.129 & $-8.149(6.741)$ & 0.227 & $-9.056(5.960)$ & 0.129 & $-9.016(6.083)$ & 0.139 \\
\hline RBANS Index II & \multicolumn{2}{|c|}{$\mathrm{R}^{2}=0.150$} & \multicolumn{2}{|c|}{$\mathrm{R}^{2}=0.150$} & \multicolumn{2}{|c|}{$\mathrm{R}^{2}=0.154$} & \multicolumn{2}{|c|}{$\mathrm{R}^{2}=0.150$} \\
\hline BMI & $0.256(0.097)$ & 0.008 & $0.255(0.099)$ & 0.010 & $0.249(0.097)$ & 0.010 & $0.240(0.098)$ & 0.014 \\
\hline WHR & $-0.679(6.905)$ & 0.922 & $-0.425(6.944)$ & 0.951 & $-0.393(6.894)$ & 0.955 & $1.224(7.059)$ & 0.862 \\
\hline RBANS Index III & \multicolumn{2}{|c|}{$\mathrm{R}^{2}=0.093$} & \multicolumn{2}{|c|}{$\mathrm{R}^{2}=0.095$} & \multicolumn{2}{|c|}{$\mathrm{R}^{2}=0.094$} & \multicolumn{2}{|c|}{$\mathrm{R}^{2}=0.099$} \\
\hline BMI & $0.451(0.072)$ & $<0.001$ & $0.463(0.073)$ & $<0.001$ & $0.448(0.072)$ & $<0.001$ & $0.447(0.072)$ & $<0.001$ \\
\hline WHR & $-7.253(5.107)$ & 0.156 & $-6.611(5.132)$ & 0.198 & $-7.187(5.106)$ & 0.159 & $-6.772(5.212)$ & 0.194 \\
\hline RBANS Index IV & \multicolumn{2}{|c|}{$\mathrm{R}^{2}=0.164$} & \multicolumn{2}{|c|}{$\mathrm{R}^{2}=0.168$} & \multicolumn{2}{|c|}{$\mathrm{R}^{2}=0.170$} & \multicolumn{2}{|c|}{$\mathrm{R}^{2}=0.165$} \\
\hline BMI & $0.119(0.075)$ & 0.113 & $0.141(0.077)$ & 0.066 & $0.112(0.075)$ & 0.138 & $0.112(0.076)$ & 0.108 \\
\hline WHR & $-11.469(5.353)$ & 0.032 & $-10.346(5.383)$ & 0.055 & $-11.099(5.338)$ & 0.038 & $-10.470(5.489)$ & 0.057 \\
\hline
\end{tabular}




\begin{tabular}{|c|c|c|c|c|c|c|c|c|}
\hline RBANS Index V & \multicolumn{2}{|c|}{$\mathrm{R}^{2}=0.097$} & \multicolumn{2}{|c|}{$\mathrm{R}^{2}=0.097$} & \multicolumn{2}{|c|}{$\mathrm{R}^{2}=0.097$} & \multicolumn{2}{|c|}{$\mathrm{R}^{2}=0.103$} \\
\hline BMI & $0.451(0.095)$ & $<0.001$ & $0.442(0.097)$ & $<0.001$ & $0.451(0.096)$ & $<0.001$ & $0.467(0.096)$ & $<0.001$ \\
\hline WHR & $-11.200(6.810)$ & 0.100 & $-12.359(6.841)$ & 0.071 & $-11.209(6.813)$ & 0.100 & $-10.678(6.944)$ & 0.124 \\
\hline RBANS Total Scale & \multicolumn{2}{|c|}{$\mathrm{R}^{2}=0.189$} & \multicolumn{2}{|c|}{$\mathrm{R}^{2}=0.181$} & \multicolumn{2}{|c|}{$\mathrm{R}^{2}=0.191$} & \multicolumn{2}{|c|}{$\mathrm{R}^{2}=0.194$} \\
\hline BMI & $0.395(0.074)$ & $<0.001$ & $0.399(0.084)$ & $<0.001$ & $0.390(0.074)$ & $<0.001$ & $0.392(0.075)$ & $<0.001$ \\
\hline WHR & $-10.661(5.287)$ & 0.044 & $-12.050(6.085)$ & 0.048 & $-10.451(5.285)$ & 0.048 & $-9.516(5.397)$ & 0.078 \\
\hline MMSE & \multicolumn{2}{|c|}{$\mathrm{R}^{2}=0.146$} & \multicolumn{2}{|c|}{$\mathrm{R}^{2}=0.144$} & \multicolumn{2}{|c|}{$\mathrm{R}^{2}=0.147$} & \multicolumn{2}{|c|}{$\mathrm{R}^{2}=0.146$} \\
\hline BMI & $0.021(0.009)$ & 0.018 & $0.021(0.009)$ & 0.025 & $0.021(0.009)$ & 0.021 & $0.022(0.009)$ & 0.016 \\
\hline WHR & $-0.511(0.643)$ & 0.427 & $-0.623(0.646)$ & 0.335 & $-0.502(0.643)$ & 0.435 & $-0.449(0.658)$ & 0.495 \\
\hline $\operatorname{FAB}(\log )$ & \multicolumn{2}{|c|}{$\mathrm{R}^{2}=0.181$} & \multicolumn{2}{|c|}{$\mathrm{R}^{2}=0.178$} & \multicolumn{2}{|c|}{$\mathrm{R}^{2}=0.182$} & \multicolumn{2}{|c|}{$\mathrm{R}^{2}=0.178$} \\
\hline BMI & $-0.007(0.002)$ & $<0.001$ & $-0.007(0.002)$ & $<0.001$ & $-0.007(0.002)$ & $<0.001$ & $-0.007(0.002)$ & $<0.001$ \\
\hline WHR & $0.170(0.117)$ & 0.146 & $0.180(0.117)$ & 0.125 & $0.172(0.117)$ & 0.142 & $0.149(0.120)$ & 0.212 \\
\hline
\end{tabular}

Model 1: Age, Education (Duration schooling), Sex (male), BMI, WHR, Current smoker, Past smoker, TUG, Total IADL

Model 2: Model 1 + Haemoglobin A1C (HbA1C)

Model 3: Model $1+$ cerebrovascular diseases(transient ischaemic attack and/or stroke)

Model 4: Model $1+\mathrm{c}$-reactive protein $(\mathrm{CRP})$

Abbreviations: BMI-Body Mass Index, WHR- Waist-Hip Ratio, TUG- Timed-Up-and-Go, IADL- Instrumental Activities of Daily Living,

MMSE-Mini-Mental State Examination, FAB-Frontal Assessment Battery, RBANS-Repeatable Battery for the Assessment of

Neuropsychological Status

Table 4: Adiposity versus Cognitive function in TUDA Bone Cohort $(\mathrm{N}=1248)$

\begin{tabular}{|l|l|l|l|l|}
\hline & Model 1 & Model 2 & Model 3 & Model 4 \\
\hline
\end{tabular}




\begin{tabular}{|c|c|c|c|c|c|c|c|c|}
\hline Cognitive Test & $\beta(\mathbf{S E})$ & P-value & $\beta(\mathbf{S E})$ & P-value & $\beta(\mathbf{S E})$ & P-value & $\beta(\mathbf{S E})$ & P-value \\
\hline RBANS Index I & \multicolumn{2}{|c|}{$\mathrm{R}^{2}=0.121$} & \multicolumn{2}{|c|}{$\mathrm{R}^{2}=0.148$} & \multicolumn{2}{|c|}{$\mathrm{R}^{2}=0.125$} & \multicolumn{2}{|c|}{$\mathrm{R}^{2}=0.139$} \\
\hline BMI & $0.021(0.097)$ & 0.831 & $0.013(0.103)$ & 0.902 & $0.031(0.097)$ & 0.753 & $-0.046(0.098)$ & 0.638 \\
\hline WHR & $-11.285(6.781)$ & 0.096 & $-10.462(7.211)$ & 0.147 & $-10.841(6.772)$ & 0.110 & $-6.623(6.836)$ & 0.333 \\
\hline RBANS Index II & \multicolumn{2}{|c|}{$\mathrm{R}^{2}=0.182$} & \multicolumn{2}{|c|}{$\mathrm{R}^{2}=0.201$} & \multicolumn{2}{|c|}{$\mathrm{R}^{2}=0.183$} & \multicolumn{2}{|c|}{$\mathrm{R}^{2}=0.185$} \\
\hline BMI & $0.033(0.108)$ & 0.762 & $0.007(0.115)$ & 0.949 & $0.039(0.108)$ & 0.717 & $0.030(0.110)$ & 0.783 \\
\hline WHR & $-25.456(7.524)$ & 0.001 & $-28.541(8.085)$ & $<0.001$ & $-25.152(7.523)$ & 0.001 & $-26.001(7.698)$ & 0.001 \\
\hline RBANS Index III & \multicolumn{2}{|c|}{$\mathrm{R}^{2}=0.071$} & \multicolumn{2}{|c|}{$\mathrm{R}^{2}=0.093$} & \multicolumn{2}{|c|}{$\mathrm{R}^{2}=0.072$} & \multicolumn{2}{|c|}{$\mathrm{R}^{2}=0.078$} \\
\hline BMI & $0.013(0.071)$ & 0.858 & $0.079(0.074)$ & 0.288 & $0.016(0.071)$ & 0.816 & $0.037(0.072)$ & 0.611 \\
\hline WHR & $-1.174(4.960)$ & 0.813 & $-1.073(5.191)$ & 0.836 & $-1.004(4.961)$ & 0.840 & $-0.241(5.027)$ & 0.962 \\
\hline RBANS Index IV & \multicolumn{2}{|c|}{$\mathrm{R}^{2}=0.198$} & \multicolumn{2}{|c|}{$\mathrm{R}^{2}=0.221$} & \multicolumn{2}{|c|}{$\mathrm{R}^{2}=0.201$} & \multicolumn{2}{|c|}{$\mathrm{R}^{2}=0.203$} \\
\hline BMI & $-0.040(0.097)$ & 0.683 & $-0.012(0.104)$ & 0.912 & $-0.030(0.097)$ & 0.757 & $-0.049(0.100)$ & 0.623 \\
\hline WHR & $-14.152(6.788)$ & 0.037 & $-13.827(7.288)$ & 0.058 & $-13.676(6.781)$ & 0.044 & $-12.871(6.943)$ & 0.064 \\
\hline RBANS Index V & \multicolumn{2}{|c|}{$\mathrm{R}^{2}=0.114$} & \multicolumn{2}{|c|}{$\mathrm{R}^{2}=0.126$} & \multicolumn{2}{|c|}{$\mathrm{R}^{2}=0.114$} & \multicolumn{2}{|c|}{$\mathrm{R}^{2}=0.124$} \\
\hline BMI & $0.039(0.090)$ & 0.660 & $0.026(0.096)$ & 0.787 & $0.042(0.090)$ & 0.637 & $0.021(0.091)$ & 0.821 \\
\hline WHR & $-5.907(6.264)$ & 0.346 & $-11.377(6.724)$ & 0.091 & $-5.783(6.269)$ & 0.356 & $-2.867(6.351)$ & 0.652 \\
\hline RBANS Total Scale & \multicolumn{2}{|c|}{$\mathrm{R}^{2}=0.228$} & \multicolumn{2}{|c|}{$\mathrm{R}^{2}=0.259$} & \multicolumn{2}{|c|}{$\mathrm{R}^{2}=0.231$} & \multicolumn{2}{|c|}{$\mathrm{R}^{2}=0.239$} \\
\hline BMI & $0.010(0.089)$ & 0.908 & $0.028(0.095)$ & 0.764 & $0.018(0.089)$ & 0.840 & $-0.010(0.091)$ & 0.914 \\
\hline WHR & $-15.440(6.206)$ & 0.013 & $-17.877(6.621)$ & 0.007 & $-15.053(6.200)$ & 0.015 & $-13.243(6.320)$ & 0.036 \\
\hline MMSE & \multicolumn{2}{|c|}{$\mathrm{R}^{2}=0.154$} & \multicolumn{2}{|c|}{$\mathrm{R}^{2}=0.160$} & \multicolumn{2}{|c|}{$\mathrm{R}^{2}=0.155$} & \multicolumn{2}{|c|}{$\mathrm{R}^{2}=0.156$} \\
\hline BMI & $-0.009(0.010)$ & 0.336 & $-0.011(0.010)$ & 0.285 & $-0.009(0.010)$ & 0.371 & $-0.013(0.010)$ & 0.202 \\
\hline WHR & $-1.824(0.672)$ & 0.007 & $-1.763(0.729)$ & 0.016 & $-1.795(0.672)$ & 0.008 & $-1.533(0.688)$ & 0.026 \\
\hline $\mathbf{F A B}(\log )$ & \multicolumn{2}{|c|}{$\mathrm{R}^{2}=0.149$} & \multicolumn{2}{|c|}{$\mathrm{R}^{2}=0.167$} & \multicolumn{2}{|c|}{$\mathrm{R}^{2}=0.155$} & \multicolumn{2}{|c|}{$\mathrm{R}^{2}=0.144$} \\
\hline BMI & $0.002(0.002)$ & 0.267 & $0.002(0.002)$ & 0.227 & $0.002(0.002)$ & 0.325 & $0.002(0.002)$ & 0.263 \\
\hline WHR & $0.111(.124)$ & 0.369 & $0.064(0.134)$ & 0.635 & $0.101(0.124)$ & 0.415 & $0.092(0.128)$ & 0.470 \\
\hline
\end{tabular}

Model 1: Age, Education (Duration schooling), Sex (male), BMI, WHR, Current smoker, Past smoker, TUG, Total IADL Model 2: Model $1+$ Haemoglobin A1C (HbA1C)

Model 3: Model $1+$ cerebrovascular diseases(transient ischaemic attack and/or stroke)

Model 4: Model $1+\mathrm{c}$-reactive protein (CRP) 
Abbreviations: BMI-Body Mass Index, WHR- Waist-Hip Ratio, TUG- Timed-Up-and-Go, IADL- Instrumental Activities of Daily Living, MMSE-Mini-Mental State Examination, FAB-Frontal Assessment Battery, RBANS-Repeatable Battery for the Assessment of

Neuropsychological Status

Table 5: Adiposity versus Cognitive function in TUDA Hypertensive Cohort $(\mathrm{N}=1909)$

\begin{tabular}{|c|c|c|c|c|c|c|c|c|}
\hline \multirow[b]{2}{*}{ Cognitive Test } & \multicolumn{2}{|l|}{ Model 1} & \multicolumn{2}{|c|}{ Model 2} & \multicolumn{2}{|c|}{ Model 3} & \multicolumn{2}{|l|}{ Model 4} \\
\hline & $\beta(\mathbf{S E})$ & P-value & $\beta(\mathbf{S E})$ & P-value & $\beta(\mathbf{S E})$ & P-value & $\beta(\mathbf{S E})$ & P-value \\
\hline RBANS Index I & \multicolumn{2}{|c|}{$\mathrm{R}^{2}=0.165$} & \multicolumn{2}{|c|}{$\mathrm{R}^{2}=0.166$} & \multicolumn{2}{|c|}{$\mathrm{R}^{2}=0.166$} & \multicolumn{2}{|c|}{$\mathrm{R}^{2}=0.162$} \\
\hline BMI & $0.110(0.077)$ & 0.152 & $0.120(0.078)$ & 0.124 & $0.107(0.077)$ & 0.163 & $0.112(0.079)$ & 0.152 \\
\hline WHR & $-21.993(5.241)$ & $<0.001$ & $-21.006(5.311)$ & $<0.001$ & $-21.991(5.240)$ & $<0.001$ & $-21.229(5.326)$ & $<0.001$ \\
\hline RBANS Index II & \multicolumn{2}{|c|}{$\mathrm{R}^{2}=0.207$} & \multicolumn{2}{|c|}{$\mathrm{R}^{2}=0.208$} & \multicolumn{2}{|c|}{$\mathrm{R}^{2}=0.208$} & \multicolumn{2}{|c|}{$\mathrm{R}^{2}=0.210$} \\
\hline BMI & $-0.002(0.084)$ & 0.980 & $0.020(0.085)$ & 0.818 & $-0.005(0.084)$ & 0.954 & $-0.038(0.086)$ & 0.655 \\
\hline WHR & $-18.552(5.750)$ & 0.001 & $-17.277(5.820)$ & 0.003 & $-18.533(5.749)$ & 0.001 & $-18.217(5.821)$ & 0.002 \\
\hline RBANS Index III & \multicolumn{2}{|c|}{$\mathrm{R}^{2}=0.141$} & \multicolumn{2}{|c|}{$\mathrm{R}^{2}=0.140$} & \multicolumn{2}{|c|}{$\mathrm{R}^{2}=0.141$} & \multicolumn{2}{|c|}{$\mathrm{R}^{2}=0.146$} \\
\hline BMI & $0.079(0.048)$ & 0.096 & $0.080(0.048)$ & 0.098 & $0.080(0.048)$ & 0.095 & $0.076(0.048)$ & 0.117 \\
\hline WHR & $-9.729(3.253)$ & 0.003 & $-9.883(3.291)$ & 0.003 & $-9.729(3.253)$ & 0.003 & $-9.320(3.282)$ & 0.005 \\
\hline RBANS Index IV & \multicolumn{2}{|c|}{$\mathrm{R}^{2}=0.158$} & \multicolumn{2}{|c|}{$\mathrm{R}^{2}=0.158$} & \multicolumn{2}{|c|}{$\mathrm{R}^{2}=0.159$} & \multicolumn{2}{|c|}{$\mathrm{R}^{2}=0.156$} \\
\hline BMI & $0.038(0.080)$ & 0.632 & $0.049(0.081)$ & 0.545 & $0.036(0.080)$ & 0.650 & $0.052(0.081)$ & 0.525 \\
\hline WHR & $-3.451(5.465)$ & 0.528 & $-2.180(5.532)$ & 0.694 & $-3.461(5.466)$ & 0.527 & $-4.112(5.538)$ & 0.458 \\
\hline RBANS Index V & \multicolumn{2}{|c|}{$\mathrm{R}^{2}=0.127$} & \multicolumn{2}{|c|}{$\mathrm{R}^{2}=0.128$} & \multicolumn{2}{|c|}{$\mathrm{R}^{2}=0.127$} & \multicolumn{2}{|c|}{$\mathrm{R}^{2}=0.124$} \\
\hline BMI & $0.107(0.080)$ & 0.183 & $0.100(0.081)$ & 0.220 & $0.105(0.080)$ & 0.190 & $0.079(0.082)$ & 0.340 \\
\hline WHR & $-21.280(5.483)$ & $<0.001$ & $-21.243(5.549)$ & $<0.001$ & $-21.278(5.484)$ & $<0.001$ & $-20.640(5.587)$ & $<0.001$ \\
\hline
\end{tabular}




\begin{tabular}{|c|c|c|c|c|c|c|c|c|}
\hline RBANS Total Scale & \multicolumn{2}{|c|}{$\mathrm{R}^{2}=0.260$} & \multicolumn{2}{|c|}{$\mathrm{R}^{2}=0.260$} & \multicolumn{2}{|c|}{$\mathrm{R}^{2}=0.260$} & \multicolumn{2}{|c|}{$\mathrm{R}^{2}=0.258$} \\
\hline BMI & $0.076(0.065)$ & 0.241 & $0.084(0.066)$ & 0.200 & $0.074(0.065)$ & 0.252 & $0.063(0.066)$ & 0.342 \\
\hline WHR & $-18.390(4.437)$ & $<0.001$ & $-17.546(4.498)$ & $<0.001$ & $-18.394(4.437)$ & $<0.001$ & $-18.048(4.505)$ & $<0.001$ \\
\hline MMSE & \multicolumn{2}{|c|}{$\mathrm{R}^{2}=0.125$} & \multicolumn{2}{|c|}{$\mathrm{R}^{2}=0.126$} & \multicolumn{2}{|c|}{$\mathrm{R}^{2}=0.125$} & \multicolumn{2}{|c|}{$\mathrm{R}^{2}=0.124$} \\
\hline BMI & $-0.001(0.007)$ & 0.929 & $-0.001(0.007)$ & 0.938 & $-0.001(0.007)$ & 0.912 & $-0.002(0.007)$ & 0.730 \\
\hline WHR & $-1.457(0.480)$ & 0.002 & $-1.442(0.486)$ & 0.003 & $-1.457(0.480)$ & 0.002 & $-1.397(0.486)$ & 0.004 \\
\hline FAB $(\log )$ & \multicolumn{2}{|c|}{$\mathrm{R}^{2}=0.125$} & \multicolumn{2}{|c|}{$\mathrm{R}^{2}=0.126$} & \multicolumn{2}{|c|}{$\mathrm{R}^{2}=0.126$} & \multicolumn{2}{|c|}{$\mathrm{R}^{2}=0.125$} \\
\hline BMI & $-0.001(0.001)$ & 0.403 & $-0.001(0.001)$ & 0.281 & $-0.001(0.001)$ & 0.420 & $-0.001(0.001)$ & 0.524 \\
\hline WHR & $0.221(0.090)$ & 0.014 & $0.200(0.091)$ & 0.028 & $0.221(0.090)$ & 0.014 & $0.198(0.091)$ & 0.030 \\
\hline
\end{tabular}

Model 1: Age, Education (Duration schooling), Sex (male), BMI, WHR, Current smoker, Past smoker, TUG, Total IADL Model 2: Model 1 + Haemoglobin A1C (HbA1C)

Model 3: Model $1+$ cerebrovascular diseases(transient ischaemic attack and/or stroke)
Model 4: Model $1+$ c-reactive protein (CRP)

Abbreviations: BMI-Body Mass Index, WHR- Waist-Hip Ratio, TUG- Timed-Up-and-Go, IADL- Instrumental Activities of Daily Living, MMSE-Mini-Mental State Examination, FAB-Frontal Assessment Battery, RBANS-Repeatable Battery for the Assessment of

Neuropsychological Status 